\title{
Relações sociais na educação infantil: olhar sobre o corpo e os sentimentos
}

\author{
Social relationships in early childhood education: look at the body and feelings
Las relaciones sociales en el contexto de la educación de la primera infancia: una mirada en el cuerpo y los sentimientos

\author{
MÁRCIA BUSS-SIMÃO*
}

\begin{abstract}
RESUMO - Este artigo apresenta resultados de uma pesquisa em que as análises das relações sociais entre crianças pequenas num contexto de educação infantil evidenciam a centralidade da dimensão corporal em suas ações e relações. Nas análises, o modo como as crianças se colocam espacialmente em relação às outras torna evidente a centralidade do corpo, do toque, do tato, do afeto e da proximidade nas relações que elas estabelecem entre si e com os adultos. As crianças apontam uma forma particular de se relacionar corporal e fisicamente com seus pares e com o mundo, tocando e se aproximando de seus pares e também dos adultos, indicando que a dimensão corporal, enquanto mediadora das relações, envolve também elementos sensoriais e emocionais. As crianças, nas suas ações, enunciam ainda uma relação com o corpo como experiência que se encontra vinculado ao mundo social e material. Isso permite supor que, para as crianças, a partir de suas perspectivas, seus mundos e elas mesmas não são separados e elas não se veem por partes nem separadas de suas experiências, de seus processos, acontecimentos e espaços, com os quais estão envolvidas.
\end{abstract}

Palavras-chave - Educação infantil. Relações sociais. Dimensão corporal. Perspectiva das crianças.

\begin{abstract}
This article presents results of a survey in which the analysis of social relations among young children in the context of early childhood education highlight the centrality of body dimension in their actions and relationships. In the analysis, the way children are placed spatially in relation to others, makes clear the centrality of the body, touch, feel, affection and proximity in the relations hips they establish with each other and with adults. Children show a particular way of relating body and physically with their peers and with the world, playing and approaching their peers and also adults, indicating that corporal dimension, as a mediator of the relationship also involves sensory and emotion al elements. Children, in their actions, set out a parallel with the body as experience that is bound to the social and material world. This suggests that, for children, from their perspectives, their worlds and themselves are not separate, they are not seen by the parties and not separated from their experiences, processes, events and spaces, which are involved.
\end{abstract}

Keywords - Early childhood education. Social relationships. Bodysise. Perspective of children.

RESUMEN - Este trabajo presenta los resultados de una investigación en que el análisis de las relaciones sociales entre los niños pequeños en el contexto de la educación de la primera infancia demuestra la importancia del tamaño del cuerpo en sus acciones y relaciones. En el análisis, la forma en que los niños se colocan en el espacio en relación a otros se hace evidente la centralidad del cuerpo, del toque, del tacto, del afecto y la cercanía en las relaciones que establecen entre ellos y con los adultos. Los niños apuntan a una forma particular de relación corporal y física con sus pares y con el mundo, tocando y acercándose a sus compañeros y también a los adultos, lo que indica que el tamaño del cuerpo como mediador de la relación también implica elementos sensoriales y emocionales. Los niños, en sus acciones, sin embargo, indican una relación con el cuerpo como experiencia que se en laza con el mundo social y material. Esto permite suponer que, para los niños, desde sus perspectivas, sus mundos y ellos mismos no están separados y ellos no ven a sí mismos por partes o separadas de sus experiencias, sus procesos, sus eventos y espacios, con los que están involucrados.

Palabras clave - La educación de los niños. Las relaciones sociales. El tamaño del cuerpo. Perspectiva de los niños.

\footnotetext{
* Doutora em Educação pela Universidade Federal de Santa Catarina (Florianópolis, SC, Brasil) e Professora na Universidade do Sul de Santa Catarina (Tubarão, SC, Brasil). E-mail: <marciabsimao@bol.com.br>.
} 


\section{UMA APROXIMAÇÃO À TEMÁTICA E BREVE CONTEXTUALIZAÇÃO DO CAMPO}

Estudos e pesquisas no âmbito da pequena infância, mais particularmente na educação infantil, têm buscado elementos para a constituição de uma especificidade da ação docente na educação infantil. Nesse empenho há ainda muitos desafios com vistas a superar visões negativas dessa profissão que envolve as esferas privada e pública, bem como, a decorrente desvalorização das ocupações diretamente associadas ao mundo feminino em que a competência profissional é questionada em virtude de sua proximidade com o doméstico, com as relações emotivas e os contatos corporais. Essa desvalorização é resultado, em especial, de uma contraposição das ocupações que se convencionou chamar de universo masculino de trabalho, geralmente identificado com o espaço público, em que as relações de impessoalidade predominam.

Para Carvalho (1999), a própria produção acadêmica, especialmente dos anos 1980, colaborou para acentuar a visão negativa que opõe de forma excludente a competência profissional ao modelo feminino de prática docente. Essa tensão entre impessoalidade e envolvimento emocional impede, por exemplo, de se considerar o afeto, o carinho e o amor como qualidades da profissão e não como falta de profissionalismo.

Além dessas questões, Haddad, Cordeiro e Monaco (2012) apontam as tensões decorrentes da dicotomia entre a esfera privada e a pública, que opõe as práticas de cuidados às práticas escolares. As primeiras, por envolverem atividades que requerem contatos corporais e trocas emocionais constantes com as crianças, estariam mais próximas do espaço doméstico, portanto consideradas menos profissionais; já as segundas, pela sua proximidade ao caráter formal da escola e, portanto, do espaço público, teriam maior legitimidade profissional. Essa tensão se faz presente nas ações cotidianas na educação infantil, repercutindo na compreensão dicotomizada entre o cuidar e o educar. Essa repercussão induziu a uma compreensão do termo "pedagógico" como associado às atividades mais "nobres", passando a ser utilizado para distinguir atividades "nobres" de atividades menos "nobres". Nesse julgamento de valor, as atividades menos "nobres" seriam as voltadas ao cuidado, sobretudo com a dimensão corporal que a educação das crianças pequenas envolve.

Por outro lado, as atividades mais "nobres" e com mais status seriam aquelas relacionadas com o termo educação e, sobretudo, relacionadas com a dimensão cognitiva, mantendo também uma relação com um produto final, com resultados e desempenhos observáveis. Nesse sentido, as atividades denominadas "pedagógicas" abarcam especialmente: jogos dirigidos, colagens, recortes e desenhos coletivos, contação de histórias e, mais particularmente ainda, aquelas atividades voltadas ao ensino da leitura e da escrita. Sendo essas atividades "pedagógicas" muitas vezes compreendidas, pelos profissionais que atuam diretamente com as crianças, como aquelas atividades que ensinam algo para as crianças.

Essa perspectiva vem sendo questionada, sobretudo pelos estudos e reflexões do que tem sido definido como Pedagogia da Infância em que se concebe ser fundamental não tomar como base de um projeto educacional pedagógico o conteúdo em sua versão escolar, especialmente, aqueles pautados numa visão do ensino como mera transmissão. Na mesma proporção, concebe-se essencial tirar as crianças da posição periférica ou da posição de subalternidade frente às discussões pedagógicas que lhes dizem respeito. Para tanto, diversas iniciativas buscam articular os segmentos da política, da pesquisa e da educação para a construção e consolidação de uma Pedagogia da Infância, objetivando delimitar uma especificidade da ação educativa junto às crianças de $0 \mathrm{a}$ 6 anos em instituições de educação infantil. Algumas dessas articulações se concretizaram nas Diretrizes Curriculares Nacionais para Educação Infantil ao definirem:

Art. $4^{\circ}$ As propostas pedagógicas da Educação Infantil deverão considerar que a criança, centro do planejamento curricular, é sujeito histórico e de direitos que, nas interações, relações e práticas cotidianas que vivencia, constrói sua identidade pessoal e coletiva, brinca, imagina, fantasia, deseja, aprende, observa, experimenta, narra, questiona e constrói sentidos sobre a natureza e a sociedade, produzindo cultura (BRASIL, 2009, p. 1).

Assim, tendo como marca a função social atribuída à Educação Infantil, na perspectiva de uma Pedagogia da Infância, concebe-se como fundamental que a dimensão que os conhecimentos assumem na educação das crianças pequenas se dá de modo vinculado aos processos gerais que as constituem: as linguagens, as interações, os jogos e as brincadeiras. Outrossim, as interações, os jogos, as linguagens, a ação intencional e a mediação qualificada apontam para a orientação e sistematização de ações educativas que tenham como eixo de sua organização as próprias crianças e seus processos de constituição como seres humanos, como apontam Rocha e Ostetto (2008).

Dessa forma, se concebe que todos os tempos, todas as organizações, disposições e arranjos espaciais e todas as relações que as crianças estabelecem entre si e com os adultos e destes com as crianças constituem-se como educacionais e pedagógicas. Nessa perspectiva se compreende que o conhecimento é parte e consequência das relações que as crianças estabelecem com o meio natural, com o meio social, com a cultura, com os adultos e com as outras crianças. Para Rocha (2008), a ação educativa 
envolve um compromisso com o desenvolvimento e a aprendizagem das crianças por meio da ampliação das experiências próximas e cotidianas, objetivando uma apropriação de conhecimentos no âmbito mais ampliado e plural, porém sem finalidade cumulativa ou caráter de terminalidade em relação à elaboração de conceitos.

Também, nessa concepção, busca-se uma compreensão que não sobreponha valores demarcando atividades "mais nobres" ou "menos nobres" no que se refere às ações que envolvem o cuidado e a educação de crianças pequenas. Ainda, nessa perspectiva, não se considera da ordem do "pedagógico" somente a representação do que se manifesta nas falas, nos desenhos, nas modelagens, mas também do que se manifesta na sensorialidade, na afetividade, nas relações e proximidades, nos movimentos, nos gestos, enfim no corpo e nas suas expressões.

Nessa concepção, o desafio consiste também em reunir indicações a partir do que as crianças nos revelam, em especial a partir de pesquisas que buscam compreender e se aproximar da perspectiva das crianças a fim de compreender e apreender a contribuição única que elas possam nos dar a partir da sua condição geracional. Como indica Rocha (2008, p.46), "busca-se nessa escuta confrontar, conhecer um ponto de vista diferente daquele que nós seríamos capazes de ver e analisar no âmbito do mundo social de pertença dos adultos".

Ouvir as indicações das crianças oferece pistas que podem contribuir para a construção da especificidade da docência com crianças pequenas a qual envolve uma grande quantidade de ações, tais como: alimentar, dar banho, trocar fraldas, manter contatos corporais constantes com as crianças e estabelecer formas de relação e comunicação cuja predominância reside em manifestações emocionais e corporais. Nesse sentido, reafirma-se a necessidade de uma compreensão da ação docente sem sobreposições de valores do que sejam atividades "mais nobres" ou "menos nobres" no que se refere às ações que envolvem o cuidado e a educação de crianças pequenas. Como já afirmado acima, uma concepção, que considera da ordem do "pedagógico" também o que se manifesta na sensorialidade, na afetividade, nas relações e proximidades, no corpo e nas suas expressões.

Para tanto, é fundamental também o reconhecimento de que a dimensão corporal tem centralidade nas relações e interações sociais das crianças, para as quais o corpo se torna meio de exercer ação social, ou seja, é fonte de ação social. Considerando essa premissa, é fundamental direcionar o olhar para o corpo como uma dimensão social e como possibilidade de expressividade e ação, na busca de compreender, como Fingerson (2009, p. 220), que "o corpo está diretamente envolvido na ação social, tanto quanto exerce ação social, é como uma fonte nas interações sociais do ator", ${ }_{1}^{1}$ sem contudo negar sua dimensão biológica, a qual também está infiltrada na cultura, ou seja, há entre natureza e cultura uma mútua produção. Contribuem na busca pela consolidação dessa perspectiva os estudos de Almeida (2002), BussSimão, Medeiros, Silva e Silva Filho (2010),Fingerson (2009),James (2000),James, Jenks e Prout (2000), Le Breton (1995, 2003, 2006, 2009), Mendes e Nóbrega (2004), Prout (2000; 2004, 2005), Ribeiro (2003),Shilling (1996; 2008), Silva (1999, 2001), Turner (1992; 1996) ao destacarem que o ser humano deve ser considerado um ser biocultural, pois é, ao mesmo tempo, totalmente biológico e totalmente cultural, uma vez que no ser humano a natureza e a cultura se interpenetram através de uma lógica recursiva e o que é biológico encontrase simultaneamente infiltrado de/na cultura e vice-versa. Outro aspecto a destacar, apontado pelos pesquisadores citados, é a premência em compreender de modo menos dicotômico e fragmentado o corpo como uma interconexão entre natureza e cultura, em que ambas mantêm relações de mútua produção; para tanto, recorro a uma definição de corpo como dimensão corporal.

A opção pela denominação de dimensão corporal, como já abordada em Buss-Simão (2009), advém da preocupação que diferentes denominações trazem também diferentes concepções. O conceito de corpo tem recebido algumas denominações diferenciadas, tais como: corporeidade, que numa definição ampla se refere a uma ideia abstrata de corpo, de ser corpóreo; corporalidade, que em francês e espanhol têm distinções mínimas do termo corporeidade, mas que na língua portuguesa não difere, ou seja, significa a qualidade de ser corpo ou de ser material; - e corpo, que tem uma concepção predominante na história da filosofia como instrumento da alma.

Essa dimensão corporal é compreendida como uma categoria, na qual, na delimitação do que seja o biológico encontra-se já as marcas das reflexões e concepções que se constrói ao longo da história, ou seja, encontram-se já as marcas da cultura. A opção por esta nomenclatura visa contribuir para uma compreensão de corpo de forma menos parcial e dicotômica em que há relações de mútua produção entre ambas. Outra razão para a utilização dessa nomenclatura é porque este termo encontra afinidades com os princípios de uma Pedagogia da Infância, a qual busca tomar em consideração as diversas dimensões humanas, procurando concebê-las como não dissociadas ao tratar dos conhecimentos que possam sustentar essa pedagogia.

Nessa busca por uma aproximação às indicações das próprias crianças, em especial em assuntos que lhes digam respeito, como no caso das experiências vividas em contextos coletivos de educação, as reflexões desenvolvidas neste texto, a partir de um recorte de 
uma pesquisa de doutorado concluída no ano de 2012, pretendem trazer alguns indicativos de como as crianças usam os tempos e os espaços de uma instituição de educação infantil ao estabelecerem relações sociais entre si e com os adultos e a centralidade da dimensão corporal indicada por elas nesse processo.

Objetivando trazer uma descrição a partir da perspectiva das crianças, utilizei procedimentos metodológicos provenientes da etnografia, lançando mão de registros escritos, fotográficos e fílmicos. ${ }^{2}$ A geração de dados ${ }^{3}$ foi realizada de 3 a 4 vezes por semana, durante nove meses, em uma instituição pública de Educação Infantil da rede municipal de Florianópolis, localizada em zona urbana, que atende crianças de 0 a 6 anos de idade em período integral. $\mathrm{O}$ grupo de crianças pesquisado era composto de 12 meninas e 3 meninos com idade entre dois e três anos, sendo a grande maioria das crianças procedente de família nuclear, em que metade do grupo eram filhos únicos, a outra metade tinha um ou dois irmãos. A grande maioria, do total de crianças do grupo pesquisado enfrentava dificuldades em sua condição social e econômica.

A utilização de procedimentos provenientes da etnografia objetivou uma aproximação a um ponto de vista das crianças, pois considero que este procedimento permite e implica uma participação mais direta das crianças, sendo profícuo para os investigadores que pretendem se aproximar e conhecer a perspectiva das crianças e seus modos de vida.

\section{PROXIMIdAdes: ESTAR PERTO BEM PERTO!}

O objetivo central aqui é vislumbrar, na perspectiva das crianças, como elas usam os tempos e os espaços de uma instituição de educação infantil ao estabelecerem relações sociais entre si e com os adultos. Nessa tentativa de perceber e identificar quais outras geografias as crianças criam nesse tempo e espaço que podem revelar sua ação social, evidenciou-se como elemento central para as crianças a dimensão corporal, a qual envolve também elementos sensoriais e emocionais nos usos desse corpo.

No cotidiano da instituição observada, foi possível evidenciar uma particularidade nas relações entre as crianças quanto às distâncias entre elas ou do modo como elas se colocam espacialmente em relação às outras. Essa noção da distância espacial é definida por Hall (1977) como proxêmica, ou seja, o uso do espaço pessoal num meio social enquanto produto cultural específico. Para Hall (1977), essa distância social entre as pessoas pode ser relacionada com a distância física: (a) distância íntima (contato íntimo); (b) distância pessoal (45 a 120 cm); (c) distância social (120 a 360cm - distância das relações com desconhecidos); (d) distância pública (mais de $360 \mathrm{~cm}$ - comícios, palestras, etc.).
Ao observar como as crianças se colocam espacialmente em relação às outras e aos adultos nas suas interações, é possível evidenciar que elas se colocam numa distância íntima ou pessoal - aquela mantida nos contatos íntimos. Esses modos diferenciados de manter distâncias sociais, segundo Hall (1977), são definidos inconscientemente pelas pessoas como uma distância que seja apropriada para diferentes relacionamentos. As pessoas estabelecem também uma distância confortável para a interação pessoal e definem não verbalmente esta distância como seu espaço pessoal.

Nesses modos de se colocar espacialmente, um componente central é a dimensão corporal, a qual passa a ser um meio de comunicação nesse processo interativo. Por isso, Le Breton $(2009$, p. 46) fala em corpo como meio de comunicação em que "A substância semântica do corpo não é o som, mas os gestos, mímicas, posturas, olhares, deslocamentos e os distanciamentos do outro ou de um objeto". Nesse sentido, as crianças apontam uma forma particular de se relacionar corporal e fisicamente com seus pares e com o mundo, tocando e se aproximando de seus pares e também dos adultos, chegando perto, bem perto, para juntos verem algo.

A análise proxêmica, de como as crianças se colocam espacialmente em relação às outras, torna evidente a centralidade do corpo, do toque, do tato, do afeto e da proximidade nas relações que elas estabelecem entre si e com os adultos. Nas relações sociais entre as crianças, elas também se relacionam com a corporalidade do outro: tocar o corpo do outro, chegar bem perto do outro para, juntos, ver algo e aproximar os rostos fazem parte da proxêmica das relações das crianças. Entre os adultos, esses comportamentos causariam desconforto, mesmo aqui no Brasil onde Hall (1977), ao analisar diferentes culturas que mantêm diferentes padrões de espaço pessoal, evidenciou que nas culturas latinas, por exemplo, as distâncias relativas são menores e as pessoas não se sentem desconfortáveis quando estão próximas das outras, diferentemente do que ocorre nas culturas nórdicas.

\section{A EXPRESSÃO DE EMOÇÕES E DE SENTIMENTOS}

A partir da indicação inicial das crianças da centralidade da dimensão corporal nas relações que elas estabelecem entre si e com os adultos, elas também revelaram que essa dimensão corporal, enquanto mediadora das relações, traz elementos não somente cognitivos, mas também sensoriais e emocionais nos usos dados por elas a esse corpo. Desse modo, concordo com Shilling (2008, p. 3), o qual indica que "O interesse no corpo como central e como meio da ação social contrasta com o comportamento humano que implica sujeitos que se envolvem sensorial 
e emocionalmente (bem como cognitivamente), com seu mundo social". ${ }^{4}$ Esses elementos sensoriais e emocionais presentes nos usos do corpo - essa afirmativa não exclui os cognitivos, mas o objetivo aqui é dar visibilidade para outros elementos que, comumente, não são considerados relevantes - fazem parte das relações das crianças para as quais, na sua grande maioria, a distância social é a distância íntima e pessoal, como define Hall (1977) por meio do conceito de proxêmica.

As crianças, ao assumirem, nas suas relações, essas distâncias, se envolvem sensorial e emocionalmente, sobretudo, tocando seus corpos e o de seus colegas. Contrariando as ordens de civilidade, segundo Norbert Elias (1994, p. 200), já anunciadas em 1774 por La Salle, em seu manual de Civilité, o autor indica que a ânsia das crianças de tocarem objetos, roupas ou outras coisas deve ser corrigida "e devem ser ensinadas a tocar o que veem apenas com os olhos". Esses preceitos fazem parte de todo um processo civilizador, no qual, "o olho assume importância muito específica", retirando de cena o envolvimento sensorial com as coisas e os objetos e, sobretudo, com a dimensão corporal. As crianças, no entanto, contrariam esse pressuposto civilizador envolvendo-se sensorial e emocionalmente com seus pares e adultos, potencializando o sentido do tato e, por meio dele, exteriorizando suas emoções e a afetividade.

Ao compreender o corpo como base de toda experiência social, é preciso considerar a afetividade e as emoções nas relações estabelecidas pelas/entre crianças. Le Breton (2009) sublinha que a socialização afetiva não ensina apenas os modos como as crianças devem reagir em determinadas situações, mas também sugere o que as crianças devem sentir em determinadas situações, bem como o que e como se pode falar a respeito desse sentimento. Shott (1979), ao trazer elementos para a compreensão da emoção na vida social, indica a necessidade de investigações sociológicas da emoção para uma compreensão plena da emoção e da vida social, pois certos tipos de emoções são tão importantes para o controle social que a sociedade como a conhecemos não poderia existir sem eles. Para a autora, as normas sociais têm claramente um impacto substancial sobre a interpretação, a expressão e a excitação da emoção, constituindo-se assim também em artefatos culturais, juntamente com o campo das ideias e da cognição.

As pesquisas de Hochschild (1979) contribuem nessa compreensão ao indicar que os arranjos sociais são habitualmente regidos por "regras de sentimento" que prescrevem (ou desencorajam) certas emoções; desse modo, as pessoas costumam fazer um "trabalho emocional" sobre seus sentimentos numa tentativa de despertar as emoções que elas avaliam que devem sentir, constituindo-se num processo de "socialização" contínua de sentimentos, o qual traz considerável controle social do afeto. O autor complementa afirmando que "as normas (regras de exibição ou regras sentimento), uma vez acordadas, estabelecem o valor de um gesto e são, portanto, usadas em trocas sociais como um meio de troca" (HOCHSCHILD, 1979, p. 568). ${ }^{5}$

Le Breton (2009, p. 173) contribui com essa questão indicando que, de diversas formas, "a palavra ou o gesto formalizam a afetividade da criança e confirmam o que ela já sente ao observar a experiência dos próximos". Para essa questão, é também central a contribuição de Barbosa (2011) ao afirmar o entrelaçamento constitutivo que há entre sujeito, linguagem e emoções repercute numa concepção de que a vida afetiva nasce a partir da mediação e interação com o contexto sociocultural, em que as emoções não são compreendidas como elementos puramente corporais: "O que há é um ser que, composto por um corpo-mente, aprende a reagir, a pensar e a sentir sempre numa inter-relação com o outro e consigo mesmo" (BARBOSA, 2011, p. 23).

Com base em uma fundamentação analítica, advinda dos estudos e pesquisas da sociologia das emoções, ${ }^{6}$ as análises das emoções não se restringem aos sentimentos dos atores sociais. Mas, partindo do subjetivo que movimenta a ação do ator, procuram não se restringir a esse subjetivo e colocam o foco de sua atenção "as formas relacionais que assumem as ações sociais quando direcionadas objetivamente para um outro" (KOURY, 2009, p. 9). Desse modo, as experiências emocionais envolvidas nas interações estabelecidas conservam um padrão sócio comunicacional em que o cultural e o social correlacionam-se.

Por essa razão, Le Breton (2009, p. 120) enfatiza que "as emoções não são espontâneas, mas ritualmente organizadas. Reconhecidas em si e exibidas aos outros, elas mobilizam um vocabulário e discursos". As emoções não existem desvinculadas do relacionamento com os outros; pelo contrário, elas só ganham realidade e significado em uma determinada cultura e um contexto social específico. O antropólogo Marcel Maus, ao escrever sobre a expressão obrigatória dos sentimentos, salienta que "todas as expressões coletivas, simultâneas, de valor moral e de força obrigatória dos sentimentos do indivíduo e do grupo são mais do que simples manifestações, são sinais, expressões compreendidas, em suma, uma linguagem" (MAUSS, 2001, p. 332).

No que se refere à expressão social das emoções, Le Breton (2009) salienta ainda que, no interior de um contexto social, as manifestações corporais e afetivas de um ator carregam consigo, aos olhos de seus semelhantes, um significado virtual de um repertório cultural de seu grupo. Nesse sentido, é possível inferir que cada um 
aprende a sentir as afeições e a traduzi-las, da mesma forma como se aprende uma língua, sendo que esse processo jamais se encerra; pelo contrário, se estende por toda a vida, estando em estreita correlação com as mudanças sociais e culturais ou, ainda, decorrentes de situações particulares vividas pelos atores.

No contexto investigado, o modo como as crianças, diariamente, recebiam seus amigos é significativo desse ritual de exibição de suas emoções. Por meio de gestualidades e formas de saudações, exteriorizam um envolvimento sensorial e emocional, ao demonstrar satisfação quanto à chegada de seus amigos na instituição. Também nessa gestualidade, nesse uso social do corpo, está presente o envolvimento sensorial e emocional, traduzido na necessidade de abraçar, de pegar nas mãos, de beijar, ou seja, de tocar o corpo do outro. Aqui também a distância social é a distância íntima ou pessoal (Hall, 1977, 1994). A seguir, disponibilizo trechos das notas de campo em que nas situações de saudação as crianças fazem uso de seus corpos, traduzindo sua emoção com a chegada de seus amigos.

Estamos todos sentados no tapete, participando da roda de conversa, e a porta da sala se abre anunciando

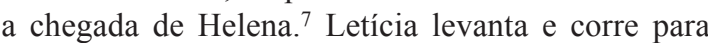
recebê-la com um abraço; ao mesmo tempo, William levanta e pega na mão de Helena e a convida para sentar ao seu lado, sendo o convite aceito pela Helena. (Registro notas de campo do dia 30-3-2009)

Estamos na roda de conversa quando Camila chega com seu pai e Larissa recebe Camila com alegria:

Larissa: oi Camila!!! Oi Camila!

Quando a Ana Laura chega, Willian corre para perto dela e lhe dá um beijo no rosto.

Em seguida, Isadora chega e Larissa se levanta e corre até a porta para recebê-la.

Larissa: Isa, Isa! (Registro notas de campo do dia 21-5-2009)

Estamos sentados na roda de conversa quando Jennyfer chega com seu pai. Willian levanta e corre até ela dando-lhe um abraço dizendo: oi amiga. Léo também se levanta e a abraça dizendo: oi amiga. Em seguida, Amanda e Ana Laura também se levantam para saudá-la. (Registro notas de campo do dia 22-5-2009)

Às 9h20min chega o Willian com sua mãe. Léo corre até ele e lhe dá um abraço e depois mais um abraço. Ana Laura também vai abraçar o Willian. (Registro notas de campo do dia 4-6-2009)

Recorrentemente, no início da manhã, observava cenas semelhantes entre as crianças, tanto por parte dos meninos como por parte das meninas. Os usos sociais dados ao corpo, nos momentos de saudação, mostram também um envolvimento sensorial e emocional e a centralidade e potencialidade do toque, da distância social íntima ou pessoal, como elementos presentes nas relações estabelecidas pelas/entre as crianças. Como aponta Le Breton (2009, p. 43): “Os gestos, as mímicas, as posturas, os deslocamentos exprimem emoções, desempenham atos, acentuam ou nuançam um discurso, manifestando significações em permanência, para si e para os demais". Nas situações de saudações, as ações das crianças com seus deslocamentos em direção a seus amigos que acabam de chegar não desempenham apenas ações motrizes, mas exprimem emoções e manifestam significados, tanto para elas mesmas como para os outros, apontando a centralidade do envolvimento emocional e sensorial como uma particularidade nos usos sociais do corpo. Da mesma forma, é possível afirmar que nessas interações sociais ocorre um trabalho de "duas vias"nas palavras de Barbosa (2011, p. 20): “[...] em um sentido, o sujeito sofre a ação dos instrumentos mobilizados por seus interlocutores para definir, regular os modos de agir, de ser daquele; em outro sentido, o sujeito lança mão desses instrumentos, das palavras, que lhes são dados pelo outro e passa a usar para pensar a si mesmo e também para agir sobre os seus interlocutores". Atentar para as indicações das crianças nos modos como se relacionam com seus pares traz elementos para compreender, como destaca Shott (1979), que as emoções não são consequências automáticas e simples respostas fisiológicas, mas sim consequências complexas de interpretação, aprendizagem e influência social.

\section{CORPO COMO EXPERIÊNCIAS NOS DODÓIS}

Outra particularidade observada entre as crianças, a qual envolve tanto a proxêmica íntima quanto um envolvimento emocional e sensorial, é a ação comum de compartilharem seus "dodóis" como uma experiência em que o corpo emerge na prática das interações como no episódio a seguir:

Letícia e mais duas meninas estão sentadas nos vasos sanitários para fazerem xixi. Letícia me mostra seus machucados: um na perna - só vejo a cicatriz - e um na palma da mão. Letícia diz que sangrou, e pergunto:

Márcia: Porque sangrou?

Letícia: Na mão e no joelho - ao mesmo tempo que toca e aponta os locais em seu corpo.

Márcia: Porque sangrou? - repito a pergunta.

Letícia: Sangrou porque o Leo me empurrou e eu escorreguei e caí.

Em seguida terminou seu xixi e disse:

Letícia: Tem que se limpar senão o bichinho vem e come a pechereca, né?

Em seguida sai para voltar ao parque (Registro notas de campo do dia 30-04-2009). 
Mostrar os seus machucados, ou seja, compartilhar os "dodóis" com os adultos e com outras crianças é recorrente entre crianças pequenas, sendo que diversas vezes fui convidada a olhar os seus "dodóis" ou, em outras situações, somente observei esse compartilhar entre elas mesmas. Numa dessas situações, a partir da afirmação da Letícia de que seu dodói havia sangrado pergunto: por que? A resposta dada pela Letícia: "Sangrou porque o Leo me empurrou e eu escorreguei e caí" traz a evidência dessa percepção do corpo como experiência e em relação com a situação vivida em que se machucou. Essa resposta dada pela Letícia encontra uma aproximação à afirmação de Christensen (2003, p. 124), de que "Crianças falam a partir de uma perspectiva de seu corpo vivido [leiblichen Körpers], de corpo como experiência, em ação, integrado com o mundo como também em interação com outros". ${ }^{8}$ Esse modo de se relacionar com a dimensão corporal sinaliza que a preocupação das crianças está na interrupção da relação com o mundo social e material e seus corpos e não uma preocupação com o ferimento da pele ou em denominar partes do corpo que estão machucadas.

Esse modo diferenciado de se relacionar com a dimensão corporal é definido por Pia Christensen (2003) como uma relação de experiência com o corpo e não uma relação somática e limitada. A autora, ao trazer análises de seus dados de campo em que investigava situações nas quais as crianças estavam doentes ou se machucavam na escola, analisa e conclui que elas têm uma relação de experiência com o corpo nessas situações. A partir das respostas das crianças, a investigadora destaca que as crianças não dão uma explicação "objetiva" de que a pele se abriu e por isso sangra, mas sempre consideram a relação em que estavam envolvidas.

Essa relação do corpo como experiência e sua relação com o mundo social e material traz uma reflexão importante para o campo educacional, pois indica que as crianças não percebem seus corpos separados dos espaços. Essa percepção se torna evidente nas perguntas dirigidas para elas, pois sempre que diziam que estavam com "dodóis" eu, automaticamente, perguntava "onde", querendo com essa pergunta saber o local específico no corpo. No entanto elas respondiam o local onde o acidente havia acontecido: lá na minha casa, na creche, na casa da prima, na rua da minha igreja, lá na árvore, lá no banco, etc., e não a parte específica do corpo que haviam machucado.

Essas respostas das crianças, por diversas vezes, fizeram com que eu me perguntasse se havia feito a pergunta de modo equivocado; no entanto, essa situação também foi evidenciada em pesquisa realizada por Christensen (2003) na qual a autora esclarece que os adultos, ao realizar a pergunta, sempre tinham a intenção de saber o local específico no corpo onde as crianças haviam se machucado, no entanto elas traziam a resposta dos locais onde haviam se machucado: no balanço, na caixa de areia, na cadeira. Essa evidência conduz a autora a afirmar que as crianças sentem seu corpo como uma realidade subjetiva e não como um "olhar de fora" sobre seu corpo como objeto. Ou seja, a lógica das crianças nas respostas para essas perguntas se dá sobre a experiência de ter-se machucado na cadeira ou a experiência de ter caído na caixa de areia ou ainda a experiência de ter sido atingida por outra criança. Desse modo, a lógica das crianças para compreenderem seu corpo não se dá tanto por meio do machucado em seu joelho ou no cotovelo, mas muito mais pela experiência da dor em ter acertado a cadeira ou caixa de areia, num sentido de uma experiência integrada entre brincar na caixa de areia e lá se machucar, havendo, com isso, uma mudança inesperada na brincadeira.

Para Christensen (2003), aqui reside dissonância e diferenciação de perspectiva entre os adultos e as crianças, pois os adultos tendem a nominar exatamente essa exterioridade do corpo como objeto nas relações com as crianças em situações de pequenos machucados “dodóis" e, por isso, dão pouca importância para essas situações, ou, ainda, insistem em minimizar essas situações com afirmações do tipo: "schh... schh... pare de chorar"; "Agora chega! não faça teatro". Christensen alerta que essa dissonância é resultado do fato de os adultos, ao desejarem compreender as experiências das crianças, utilizarem referências das experiências e traduções adultas para compreendê-las.

A compreensão do corpo como experiência indica, também, que as crianças têm ciência da continuidade de seus corpos e sua relação com o mundo social e material, da perda da posição social, da perda da atividade e da relação, bem como da mudança de seu entorno em situações em que se machucam ou ficam doentes. Isso permite supor que, para as crianças, a partir de suas perspectivas, seus mundos e elas mesmas não são separados e elas não se veem por partes nem separadas de suas experiências, de seus processos, acontecimentos e espaços com os quais estão envolvidas.

\section{CONSIDERAÇõES FINAIS}

As situações apresentadas e analisadas no texto trazem indicativos para compreender que o modo como as crianças exercem as ações e relações sociais, bem como a forma que ocupam os espaços e os tempos em uma instituição de educação infantil, são elementos a serem considerados para se compreender a vida social. As crianças, ao indicarem como fundantes de suas relações o corpo como experiência e seu entrelaçamento com as emoções e a afetividade, dão pistas de que é preciso compreender que a emoção também dá forma à vida 
social, ou seja, a dimensão corporal e as emoções se constituem meios de socialização.

O movimento crescente por uma especificidade da educação infantil e pela consolidação de uma Pedagogia da Infância tem mobilizado estudos e pesquisas a buscar alimentar o debate na área, por meio da interlocução com outros campos disciplinares, com a intenção de aprofundar a compreensão sobre as crianças e os modos de viver a(s) sua(s) infância(s). Como aponta Rocha (2008 p. 47), é nesse ponto que devem convergir os saberes de diferentes campos disciplinares com os quais "a pesquisa educacional necessita manter diálogo no sentido de conhecer o modo como as crianças vivem a sua infância e a representam, para, a partir daí, balizar a ação educativa. Nessa perspectiva, os projetos pedagógicos deixam de ser apenas para as crianças, para serem definidos a partir das crianças e com elas".

Incluir, nas ações pedagógicas, a perspectiva das crianças exige também recuperar valores e conhecimentos que incluem o corpo e suas expressões, o movimento, o gesto, o afeto, as emoções, a ludicidade, o encantamento e o maravilhamento e, sobretudo, valores e conhecimentos capazes de lidar com as polissemias e com as complementaridades, inclusive a complementaridade proporcionada pela contribuição única que as crianças podem dar, a partir da sua condição geracional, diferente daquela advinda do mundo social de pertença dos adultos.

\section{REFERÊNCIAS}

ALMEIDA, Maria da Conceição de. Borboletas, homens e rãs. Margen, São Paulo, n.15, p. 41-56, jun. 2002.

BARBOSA, Marinalva Vieira. Sujeito, linguagem e emoção a partir do diálogo entre e com Bakhtin e Vigotski. In: SMOLKA, Ana Luiza Bustamante; NOGUEIRA, Ana Lúcia Horta (Org.). Emoção, memória, imaginação: a constituição do desenvolvimento humano na história e na cultura. Campinas: Mercado de Letras, 2011.p. 11-33.

BRASIL. Ministério da Educação e Cultura. Diretrizes Curriculares Nacionais para a Educação Infantil. Resolução n. 5, de 17/12/2009, Brasília: MEC, 2009.

BUSS-SIMÃO, Márcia. A dimensão corporal: implicações no cotidiano da educação da pequena infância. Magis - Revista Internacional de Investigación em Educación, n. 3, p. 261274, 2009.

BUSS-SIMÃO, Márcia; SILVA, Ana Márcia; SILVA FILHO, João Josué da. Corpo e infância: natureza e cultura em confronto. Educação em Revista, v. 26, n. 3, p. 151-168, 2010.

CARVALHO, Marília Pinto de. No coração da sala de aula: gênero e trabalho docente nas séries iniciais. São Paulo: Xamã, 1999.

CERISARA, Ana Beatriz. Professoras de educação infantil: entre o feminino e o profissional. São Paulo: Cortez, 2002 .
CHRISTENSEN, Pia Haudrup. Kindheit und die kulturelle Konstitutionverlezlicher Körper. In: HENGST, Heinz; KELLE, Helga. Kinder - Köerper - Identitäten. Weinhein und München: Juventa, 2003. p. 115-136.

ELIAS, Norbert. O processo civilizador: uma história dos costumes. Rio de Janeiro: Jorge Zahar, 1994. v. 1.

FINGERSON, Laura. Children's bodies In: QVORTRUP, Jens; CORSARO, William A.; HONIG, Michael-Sebastian. The Palgrave handbook of childood studies. Basingstoke: Palgrave Macmillan, 2009. p. 217-227.

GRAUE, M. Elizabeth; WALSH, Daniel. Investigação etnográfica com crianças: teorias, métodos e ética. Lisboa: Fundação Calouste Gulbenkian, 2003.

HADDAD, Lenira; CORDEIRO, Maria Helena; MONACO, Gregóry Lo. As tarefas do professor de educação infantil em contextos de creche e pré-escola: buscando compreender tensões e oposições. Educação \& Linguagem, v. 15, n. 25, p. 134-154, 2012.

HALL, Edward T. A dimensão oculta. Rio de Janeiro: Francisco Alves, 1977.

1994.

A linguagem silenciosa. Lisboa: Relógio D’Água,

HOCHSCHILD, Arlie Russell. Emotion work, feeling rules, and social structure. American Journal of Sociology, v. 85, n. 3, p. 551-575, 1979.

JAMES, Alison. Embodied being(s): understanding the self and the body in childhood. In: PROUT, Alan. The body, childhood and society. London: Palgrave Macmilan, 2000. p. 19-37.

JAMES, Alison; JENKS Chris; PROUT, Alan. O corpo e a infância. In: KOHAN, Walter Omar; KENNEDY, David. Filosofia e infância: possibilidades de um encontro. 2. ed. Petrópolis: Vozes, 2000. p. 207-238.

KOURY, Mauro Guilherme Pinheiro. Emoções, Sociedade e Cultura: a categoria de análise emoções como objeto de investigação na sociologia. Curitiba: CRV, 2009.

KRAMER, Sônia. Autoria e autorização: questões éticas na pesquisa com crianças. Cadernos de Pesquisa, São Paulo, n. 116, p. 41-59, jul. 2002.

LE BRETON, David. Antropologia del cuerpo y modernidad. Buenos Aires: Nueva Visión, 1995.

Adeus ao corpo. Campinas: Papirus, 2003.

A sociologia do corpo. Petrópolis: Vozes, 2006.

As paixões ordinárias: antropologia das emoções. Petrópolis: Vozes, 2009.

MAUSS, Marcel. A expressão obrigatória dos sentimentos (rituais orais funerários australianos, 1921). In: de sociologia. São Paulo: Perspectiva, 2001. p. 325-333.

MENDES, Maria Isabel Brandão de Souza; NÓBREGA, Terezinha Petrúcia. Corpo, natureza e cultura: contribuições para a educação. Revista Brasileira de Educação, n. 27, p. 125-137, 2004.

PROUT, Alan.The body, childhood and society. London: Palgrave Macmilan, 2000.

Reconsiderar a nova sociologia da infância: para um estudo interdisciplinar das crianças. Ciclo de conferências em 
Sociologia da Infância 2003/2004. Departamento de Ciências Sociais Aplicadas. Universidade de Stirling, 2004. 23p.

The future of childhood. New York; London: Routledge Falmer, 2005.

RIBEIRO, Renato Janine. Novas fronteiras entre natureza e cultura. In: NOVAES, Adauto (Org.). O homem máquina: a ciência manipula o corpo. São Paulo: Cia. das Letras, 2003.

ROCHA, Eloisa Acires Candal. Diretrizes educacionaispedagógicas para a educação infantil. Documento elaborado para a Secretaria Municipal de Educação Infantil de Florianópolis, 2008. (mimeo)

Por que ouvir as crianças? Algumas questões para um debate científico multidisciplinar. In: CRUZ, Silvia Helena Vieira (Org.). A crianças fala: a escuta de crianças em pesquisas. São Paulo: Cortez, 2008. p. 43-51.

ROCHA, Eloisa Acires Candal; OSTETTO, Luciana Esmeralda. O estágio na formação universitária de professores de educação infantil. In: SEARA, Izabel Christine et al. (Org.). Práticas pedagógicas e estágios: diálogos com a cultura escolar. Florianópolis: Letras Contemporâneas, 2008. p. 103-116.

SHILLING, Chris. The body and social theory. London: Sage Publications, 1996.

Changing bodies: habit, crisis and criativity. Los Angeles; London; New Delhi; Singapore: Sage, 2008.

SHOTT, Susan. Emotion and social life: a symbolic interactionist analysis. American Journal of Sociology, v. 84, n. 6, p. 1317 1334, 1979.

SILVA, Ana Márcia. O corpo do mundo: reflexões acerca da expectativa de corpo na modernidade. 236p. Tese (Doutorado) - Universidade Federal de Santa Catarina, Florianópolis, 1999.

Corpo, ciência e mercado: reflexões acerca da gestação de um novo arquétipo da felicidade. Campinas: Autores Associados, 2001.

TURNER, Bryan S. Regulating Bodies: essays in medical sociology. London; New York: Routledge, 1992.
TURNER, Bryan S. The body and society. 2. ed. London; Thousand Oaks; New Delhi: Sage, 1996.

\section{Notas}

1 Agradeço ao DAAD/CAPES a bolsa de doutoramento que possibilitou a estada por um ano e quatro meses na Alemanha para aprofundamento dos estudos e o acesso aos materiais em língua alemã e inglesa. Considerando o respeito ao texto no original e minha limitação na tradução de outras línguas para a língua portuguesa, citarei, ao longo deste trabalho, o texto na língua original sempre em nota de rodapé: "[...] the body is directly engaged in agency, both as it exertsagency and as it a source of agency in theactor's social interactions" (FINGERSON, 2009, p. 220).

2 A realização da pesquisa com as crianças e o uso das transcrições das falas, bem como das imagens, foram autorizadas por escrito pelos pais das crianças envolvidas na pesquisa por meio de Termo de Consentimento Livre e Esclarecido (TCLE).

3 Utilizo o termo geração de dados, e não coleta de dados, com base em Graue e Walsh (2003), que sinalizam o fato de que os dados não "andam por aí" esperando que algum investigador os recolha, ao contrário, eles provêm das relações e das interações complexas que o investigador estabelece com o campo investigado.

4 "The interest in the body as central to the internal environment of social action, in contrast, highlights how human behavior involves subjects who engage sensorially and emotionally (as well as cognitively) with their social world."

5 " [...] rules (display rules or feeling rules), once agreed upon, establish the worth of a gesture and are thus used in social exchange as a medium of exchange."

6 Nas palavras de Koury (2009, p. 10): “A sociologia e a antropologia das emoções formam, assim, linhas analíticas recentes, calcadas na tradição científica das disciplinas mais amplas que as contêm" e que buscam nos processos analíticos enfatizar e estabelecer ligações entre as dimensões micro e macrossociológicas, bem como entender os fenômenos emocionais como fenômenos sociológicos.

7 Considerando questões éticas e aspectos de autoria e autorização (KRAMER, 2002) utilizo os primeiros nomes das crianças - em algumas situações utilizo o apelido usado entre as próprias crianças nos seus diálogos e relações - procurando não revelar o sobrenome e omitir o nome da instituição onde a pesquisa ocorreu.

8 "Kinder sprechen also aus der Perspektive des leiblichen Körpers als Erfahrung, in Aktion, integriert in die Umwelt wie auch in Interaktionen mit anderen."

Artigo recebido em maio 2013.

Aprovado em setembro 2013. 